\title{
Carcinoma of the lung presenting with digital ischaemia
}

\author{
J FIELD, IF LANE
}

From the Department of Surgery, Charing Cross Hospital, London

Non-metastatic syndromes associated with lung neoplasms are well recognised. ${ }^{1}$ In a prospective study endocrine or metabolic disorders were found in $12 \%$ of 240 patients with lung cancer. ${ }^{2}$ Venous thromboembolism occurred in $14 \%$ of 2360 patients presenting to the Mayo Clinic with primary lung neoplasm, ${ }^{3}$ but digital ischaemia as a presenting feature of carcinoma of the lung has not been previously described.

\section{Case report}

A 70 year old man presented with a five week history of intermittent pain, numbness, and cold sensitivity affecting the fingers of both hands. There was no history of embolic phenomena and his general health was good. He was a nonsmoker. His only medication was digoxin, $0.0625 \mathrm{mg}$ a day, for well controlled atrial fibrillation that had been present for 30 years.

On examination the fingers of both hands were cold and dry, and there was ulceration of the tips of the middle and ring fingers of the left hand (fig 1). Both radial and ulnar pulses were present and Allen's test gave a negative response. There was no evidence of a cervical band or rib.

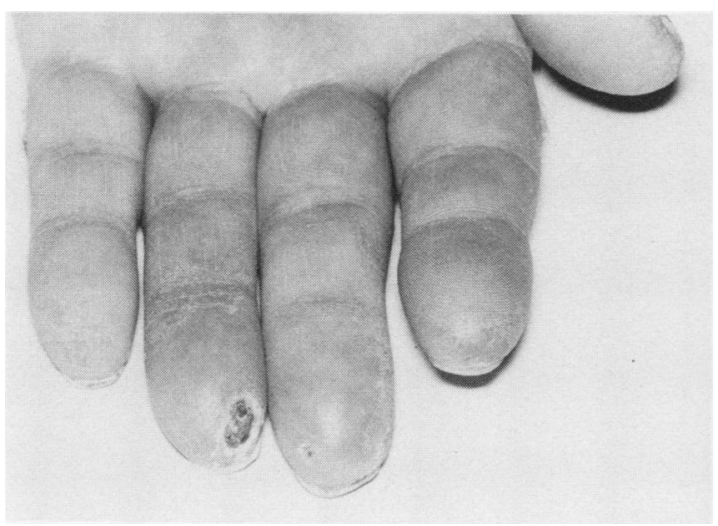

Fig 1 Deep ulcers present at the tips of the digits with fissures in the surrounding skin.

Address for reprint requests: Mr IF Lane FRCS, Department of Surgery, Charing Cross Hospital, London W6 8RF.

Accepted 20 December 1985
All foot pulses were present and there were no bruits. There were no other abnormal clinical findings.

Investigations showed: haemoglobin $13.1 \mathrm{~g} / \mathrm{dl}$, erythrocyte sedimentation rate $71 \mathrm{~mm}$ in one hour, platelet count $304 \times 10^{9} / 1$, British prothrombin ratio 1.0 , kaolin cephalin clotting time 45/46 seconds, and thrombin time $11 / 10 \mathrm{sec}-$ onds. Platelet function tests showed a slight increase in sensitivity to aggregation by adenosine diphosphate. No cold agglutinins, cryoglobulin, or cryofibrinogen were detected. Tests for antinuclear antibody, anti-Sjögrens syndrome A factor, and rheumatoid factor all gave negative results.

Electrocardiography showed atrial fibrillation and echocardiography excluded the presence of left atrial thrombus. Radiography of the hands did not show any soft tissue calcinosis, but the chest radiograph showed a solid lesion

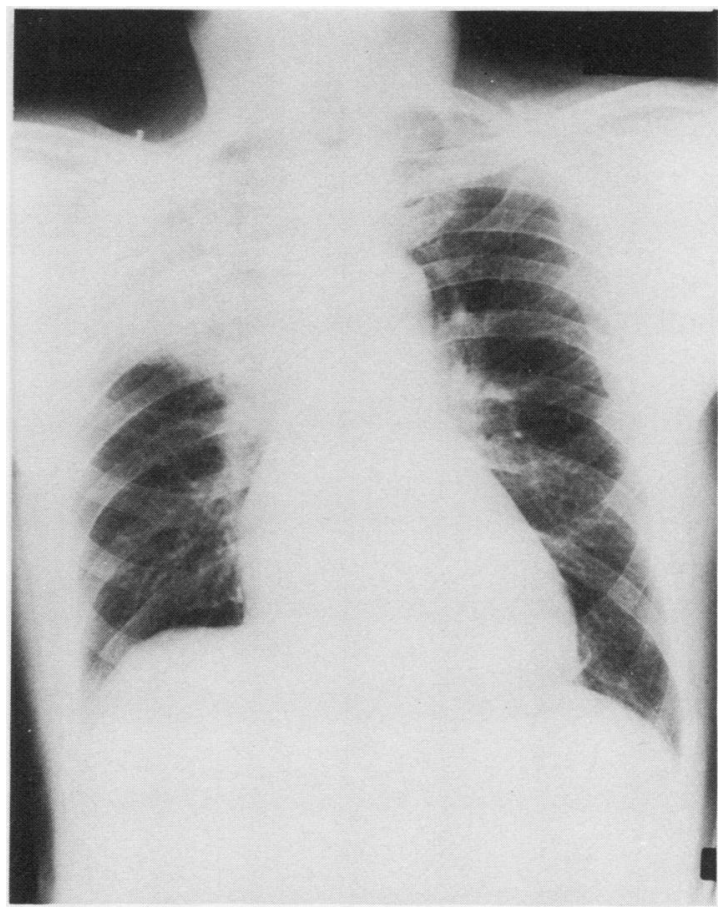

Fig 2 . Chest radiograph showing an opacity in the right upper zone. 
encircling the right upper lobe bronchus with distal pulmonary collapse (fig 2).

Fibreoptic bronchoscopy showed nothing abnormal but on mediastinoscopy malignant lymph nodes were found in both paratracheal regions, and biopsy showed a small cell anaplastic carcinoma. The patient received combination chemotherapy with radiotherapy to the right upper lung fields and mediastinum. Nine months later the tumour had regressed in size and the finger lesions were healed. There was no further digital ischaemia. The patient died 18 months after presentation.

\section{Discussion}

Sympathetic infiltration, ${ }^{4}$ thrombocytosis, ${ }^{5}$ and cryoglobulinaemia occurring in association with malignant disease have been reported to produce Raynaud's phenomenon. In this patient a source of microemboli could not be detected and there was no evidence of any appreciable haematological abnormality or connective tissue disorder. Hawley has previously reported six cases of digital ischaemia in association with malignant disease, but in none was a lung neoplasm responsible. ${ }^{6}$

The appearance of Raynaud's phenomenon in this other- wise symptomless patient preceded the diagnosis of lung. neoplasm by five weeks. Clearly, the sudden development of

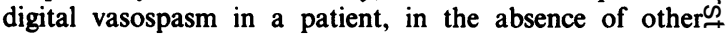
aetiological factors, demands investigation to exclude ano occult neoplasm.

We are grateful to Professor RM Greenhalgh for permission to report this case.

\section{References}

1 Hills EA. Unusual manifestations of lung cancer. Practitioner 1977;219:648-55.

2 Ransam JW, Anderson G. Incidence of paramalignant disorders in bronchogenic carcinoma. Thorax 1975;30:86-90.

3 Byrd RB, Divertie MB, Spittell JA. Bronchogenic carcinoma andthromboembolic disease. JAMA 1967;202:1019.

4 Niehan BL, Petri C. Peripheral symmetrical gangrene associated $\omega$ with metastasising carcinoma of the colon. Nord Med 1963;윽 69:237-9.

5 Spigel SC, Mooney LR. Extreme thrombocytosis associated withe malignancy. Cancer 1971;39:339-41.

6 Hawley PR, Johnston AW, Rankin JT. Association between digital ischaemia and malignant disease. Br Med J 1963;iii:208-12. 